\title{
DIVORCING PROFIT MOTIVATION FROM NEW DRUG RESEARCH: A CONSIDERATION OF PROPOSALS TO PROVIDE THE FDA WITH RELIABLE TEST DATA*
}

\author{
SIDNEY A. SHAPIRO**
}

I. INTRODUCTION............................................ 156

II. ThE DRUg TESTING Process ................................ 157

III. ETHICAL CONSIDERATIONS IN HUMAN TESTING ................. 158

IV. ThE RELATIONSHIP OF THE PROFIT Motive to RELIABLE DRUG TESTING .................................................... 161

A. The Role of the Sponsor in Drug Research ............... 162

B. The Relationship Between Sponsors and Researchers...... 163

C. Misleading or Fraudulent Industry-Generated Research ... 166

V. PRoposals For IMPROVING THE RELIABILITY OF DATA .......... 168

A. FDA Efforts ....................................... 168

B. Further Modifications in the Present System Designed to Improve the Accuracy of Experimental Data ............. 170

1. Clinical Research Standards ...................... $\quad 170$

2. Changes in Enforcement Policies ..................... 171

C. Alternatives to the Present System Designed to Improve the Accuracy of Experimental Data.......................... 175

1. Limited Third-Party Testing.......................... 175

2. Complete Third-Party Testing ......................... 177

(a) Government testing ............................ 177

(b) Independent contracting ....................... 179

VI. CONCLUSIONS AND RECOMMENDATIONS ...................... 181

* This Article is based on a report prepared for the Review Panel on New Drug Regulation of the Department of Health, Education and Welfare. However, the views expressed herein reflect the personal opinion of the author, and thus are not necessarily the views of either the Review Panel or of HEW.

The author would like to express his appreciation to the members of the Review PanelDr. Allen Astin, Professor Marsha Cohen, Dr. Charles Cornelius, Professor Norman Dorsen, Professor Robert Hamilton, Dr. David Rall and Dr. Norman Weiner-who evaluated the report on which this Article was based. The author also is appreciative of the assistance of Ms. Kathleen Buto and Mr. Jeffrey Miller, members of the Review Panel staff, who provided criticism of the same report.

** Associate Professor of Law, University of Kansas. B.S. 1970, J.D. 1973, University of Pennsylvania. 


\section{INTRODUCTION}

Under present federal regulation, a pharmaceutical company that is attempting to gain Food and Drug Administration (FDA) approval for marketing a new drug is responsible for conducting the necessary drug experimentation. ${ }^{1}$ It has been forcefully argued that because the company has a financial interest in successful test results, the present drug testing system contains an inherent bias ${ }^{2}$ that adversely affects the accuracy and acceptability of drug research. ${ }^{3}$ Concern about these effects has led to proposals that pharmaceutical research be conducted by independent parties with no financial interest in the outcome of the research. ${ }^{4}$ To evaluate whether such regulatory changes are necessary, this Article will examine the relationship between the profit-oriented testing of drugs and the need for both ethical human experimentation and accurate experimental data. Con-

THE FOLLOWING CITATIONS WILL BE USED IN THIS ARTICLE:

Examination of the Pharmaceutical Industry, 1973-74: Hearings Before the Subcomm. on Health of the Senate Comm. on Labor and Public Welfare, 93d Cong., 1st \& 2d Sess., Part 5 (1974) [hereinafter cited as Examination of the Pharmaceutical Industry (Part 5)];

Hearings on Competitive Problems in the Drug Industry Before the Subcomm. on Monopoly of the Senate Select Comm. on Small Business, 90th Cong., 2d Sess., Part 7 (1968) [hereinafter cited as Competitive Problems in the Drug Industry (Part 7)];

Hearings on Competitive Problems in the Drug Industry Before the Subcomm. on Monopoly of the Senate Select Comm. on Small Business, 91 st Cong., 1st Sess., Part 10 (1969) [hereinafter cited as Competitive Problems in the Drug Industry (Part 10)];

Hearings on Interagency Coordination in Drug Research and Regulation Before the Subcomm. on Reorganiztion and Internat'l Organizations of the Senate Comm. on Government Operations, 88th Cong., 1st Sess. (1963) [hereinafter cited as Interagency Coordination in Drug Research and Regulation];

Preclinical and Clinical Testing by the Pharmaceutical Industry, 1975, Joint Hearings Before the Subcomm. on Health of the Senate Comm. on Labor \& Public Welfare and the Subcomm. on Administrative Practice and Procedure of the Senate Comm. on the Judiciary, 94th Cong., 1st Sess., Part 1 (1975) [hereinafter cited as Preclinical and Clinical Testing (Part 1)];

Preclinical and Clinical Testing by the Pharmaceutical Industry, 1976, Joint Hearings Before the Subcomm. on Health of the Senate Comm. on Labor \& Public Welfare and the Subcomm. on Administrative Practice and Procedure of the Senate Comm. on the Judiciary, 94th Cong., 2d Sess., Part 2 (1976) [hereinafter cited as Preclinical and Clinical Testing (Part 2)];

General Accounting Office, Federal Control of New Drug Testing is Not AdeQuately Protecting Human Test Subjects and the Public, Report to the Congress (1976) [hereinafter cited as FEDERAL CONTROL OF NEW DRUG TESTING];

NATIONAL ACADEMY OF SCIENCES. EXPERIMENTS AND RESEARCH WITH HuMANS: VAlues IN CONFLICT (1975) [hereinafter cited as VALUES IN CONFLICT];

National academy of Sciences, How Safe is Safe? The Design of Policy on Drugs AND Food AdDitives (1974) [hereinafter cited as How SAFE is SAFE?].

1. See text accompanying notes 5-22 infra.

2. "Bias" as used in this Article refers to a partiality toward a certain outcome. It is not intended to indicate that the partiality is necessarily malicious.

3. See text accompanying notes 37-82 infra.

4. See text accompanying notes $135-78$ infra. 
sideration will be given to what improvements, if any, might be made in the present system.

\section{The Drug Testing Process}

Before new drugs ${ }^{5}$ can be marketed, they must be proven safe and effective to the satisfaction of the FDA. ${ }^{6}$ The necessary proof includes a three phase test ${ }^{7}$ of the drug on human beings ${ }^{8}$ and at least two wellcontrolled clinical studies. ${ }^{9}$ However, even before the research on humans can be initiated, the sponsor of the drug must submit to the FDA a Notice of Claimed Investigation Exemption for a New Drug (IND) ${ }^{10}$ containing information-including results of in vitro ${ }^{11}$ and animal studies ${ }^{12}$ on the phar-

5. Section 201(p) of the Federal Food, Drug and Cosmetic Act, 21 U.S.C. § 321(p) (1970), defines "new drug" as:

(1) Any drug . . . the composition of which is such that such drug is not generally recognized, among experts qualified by scientific training and experience to evaluate the safety and effectiveness of drugs, as safe and effective for use under the conditions prescribed, recommended, or suggested in the labeling thereof . . . .

(2) Any drug . . . the composition of which is such that such drug, as a result of investigations to determine its safety and effectiveness for use under such conditions, has become so recognized, but which has not, otherwise than in such investigations, been used to a material extent or for a material time under such conditions.

For a discussion of the difficulty faced in interpreting this section, see J. MASHAw \& $R$. Merrill, InTRoduction to the AmeriCan Public LAW System 463-66 (1975).

6. 21 U.S.C. $\$ 355$ (1970); see Weinberger v. Bentex Pharmaceuticals, 412 U.S. 645, 65254 (1973).

7. Phase I of the human testing is directed at determining the drug's chemical effects on a small number of healthy volunteers. Primer on New Drug Development, FDA CoNSUMER 12, $12-$ 13 (Feb. 1974). Phase II studies involve administering the drug to a limited number of patients who are affected with the specific disease the drug is intended to treat. During this phase, the investigators can begin to evaluate the effectiveness of the drug while additional safety testing on humans or animals continues. Id. 13. In Phase III, a large number of patients are treated in order to assess the drug's safety, effectiveness and most desirable dosage. Id. 13-14. For a detailed description of these phases, see J. GiBson, MEDICATION, LAW AND BEHAviOR 125-45 (1976).

8. Primer on New Drug Development, supra note 7, at 12, 13. The conditions under which such human experimentation may occur are prescribed by the Secretary of Health, Education and Welfare, acting pursuant to the Federal Food, Drug and Cosmetic Act. 21 U.S.C. § 355(i) (1970).

9. As used in this Article, "clinical" refers to studies on human subjects.

10. 21 U.S.C. \$ 355(a) (1970); 21 C.F.R. \$ 312.1(a)(2) (1977). Human experimentation is necessary for several important reasons, such as that a drug may affect humans differently than animals. See How SAFE IS SAFE? 109 (remarks of Oliver H. Lowry, M.D.); id. 218 (remarks of Samuel S. Epstein, M.D.). Other reasons for human experimentation are discussed in Preclinical and Clinical Testing (Part 1), at 4.

11. In vitro refers to studies performed outside of living organisms.

12. 21 C.F.R. $\& 321.1(a)(2)$ (1977). Other information submitted includes the chemical composition of the new drug, a detailed protocol intended to be used in initial clinical studies, the qualifications of the clinical investigators who will carry out the studies, an agreement by the sponsor to notify FDA and all participating investigators of any adverse effects which arise during animal or human testing, an agreement by the sponsor that it will obtain the consent of the person on whom the drug is to be tested, and agreement to submit annual progress reports. Primer on New Drug Development, supra note 7, at 12. 
macologic and toxic effects of the drug-from which the FDA can determine whether the drug appears to be reasonably safe and effective for human use. $^{13}$

If human tests are permitted, ${ }^{14}$ the sponsor may, upon completion of the necessary tests, file a New Drug Application (NDA), seeking FDA approval for marketing the drug. ${ }^{15}$ The FDA then has 180 days in which to approve or disapprove an NDA, although this review period often may be extended. ${ }^{16}$ In evaluating an NDA, the FDA reviews the sponsor's summary of the raw data derived from all the studies that were conducted. ${ }^{17}$ In addition, most FDA reviewers randomly audit certain sections of the several hundred volumes of raw data. They find it impossible, however, to review every page of the submitted information. ${ }^{18}$ If the NDA is not approved, the FDA must give the sponsor "notice of an opportunity for a hearing . . . on the question whether such application is approvable," 19 after which the FDA issues a final order either approving or refusing to approve the NDA. ${ }^{20}$

Throughout this drug testing process, all human testing is commercially sponsored. Accordingly, it is essential that certain safeguards be built into the testing system. The public must be assured that the testing of unapproved drugs in humans is conducted in an ethical manner. ${ }^{21}$ Further, the FDA must be confident that the data submitted to it by the sponsor are complete and accurate before it determines if a drug is safe and effective for its intended use. ${ }^{22}$

\section{Ethical Considerations in Human Testing}

The testing of new drugs on human beings involves subjecting selected

13. 21 C.F.R. § 312.1(a)(2) (1977); Primer on New Drug Development, supra note 7, at 12.

14. The sponsor may initiate the clinical studies unless the FDA prohibits it from doing so within 30 days of receiving the IND. 21 C.F.R. $\$ 312.1(\mathrm{a})(2)(1977)$.

15. 21 U.S.C. \$ 355(c)-(d) (1970). The statute, which rejects use of uncontrolled studies, anecdotal reports and clinical testimonials to gain new drug approval, adopted the scientific viewpoint that in light of the unpredictable course of many diseases and the biases and expectations of both patients and physicians, quantification of therapeutic benefit was not possible in the absence of formal experimental controls. Weinberger v. Hyson, Westcott \& Dunning, 412 U.S. 609, 617-20 (1973); Upjohn Co. v. Finch, 422 F.2d 944, 951-54 (6th Cir. 1970). See also Lasagna, The Pharmaceutical Revolution: Its Impact on Science and Society, 166 SCIENCE 1227, 1231 (1969).

16. 21 U.S.C. $\$ 355($ c) (1970); Review Panel on New Drug Regulation, Department of Health, Education and Welfare, Interim Report: FDA's Review of Initial IND Submissions: $A$ Study of the Process for Resolving Internal Differences and an Evaluation of Scientific Judgments (Feb. 28, 1977).

17. Review Panel on New Drug Regulations, supra note 16, at 40.

18. Id. 9,41 .

19. 21 U.S.C. \& 355(c) (1970).

20. Id. $\S 355(\mathrm{~d})$. Unfavorable decisions are appealable to the appropriate United States Court of Appeals. Id. $\S 355(\mathrm{~h})$.

21. See text accompanying notes 23-36 infra.

22. See text accompanying notes $37-82$ infra. 
portions of the population to a certain amount of risk for possible but unestablished benefits to the general public. ${ }^{23}$ The risks may be minimized and the benefits approximated by preliminary experimentation with animals, ${ }^{24}$ by thoughtful chemical analysis and through a review of past experience with similar drugs. ${ }^{25}$ Nevertheless, until a drug is tested in humans, the extent of its safety and effectiveness cannot be fully assessed. ${ }^{26}$

Human testing involves a number of ethical considerations. Among the most serious and widely discussed of these is the selection of subjects for tests. ${ }^{27}$ Subjects should be accepted only after they have given their informed consent, indicating they are fully aware of the nature and purpose of the tests and the possible risks involved. ${ }^{28}$ Thus, special problems arise in seeking the consent of persons such as prisoners, children and the mentally retarded who have questionable ability to make such meaningful decisions.

Consideration also must be paid to safeguarding the public and test subjects from needless exposure to risks that result from poorly designed tests or inaccurate or biased evaluation of test data. ${ }^{29}$ The number of test subjects exposed to experimental drugs must be large enough to establish significant levels of safety and efficacy, but not so large as to expose

23. How SAFE IS SAFE? 113 (statement of Oliver H. Lowry, M.D.); VALuES IN ConfLict 153 (remarks of J. Katz, M.D.); Dyck \& Richardson, The Moral Justification for Research Using Human Subjects, in BromediCAL ETHICS AND THE LAW 243, 243-44 (J. Humber \& R. Almeder eds. 1976); Lasagna, supra note 15, at 1227.

24. VALUES IN CONFLICT 196 (remarks of Richard Merrill and Oliver H. Lowry, M.D.); $i d$. 218 (remarks of Samuel S. Epstein, M.D.); New York Acad. of Medicine, Comm. on Public Health, The Importance of Clinical Testing in Determining the Efficacy and Safety of New Drugs, 2 J. of New Drugs 135, 138 (1962).

25. VALUES IN CONFliCr 29 (remarks of Francis D. Moore, M.D.); Trout, Problems in Drug Research and Development, in INTERSECTIONS OF LAW AND MEDICINE 59-63 (G. Morris \& M. Norton eds. 1972).

26. B. Barber, DRugs and Society 83, 84 (1967); How SAFE is SAFE? 30 (remarks of W. Clarke Wescoe, M.D.); id. 114 (remarks of Oliver H. Lowry); Dyck \& Richardson, supra note 23, at 243.

27. Preclinical and Clinical Testing (Part 1), at 350 (statement of the Pharmaceutical Manufacturers Association); VALUES IN CONFLrCT 212 (remarks of Ivan Bennett, M.D.). See generally Preclinical and Clinical Testing (Part 1); B. BARBER, supra note 26; VALUES IN CONFLICT.

28. Preclinical and Clinical Testing (Part 1), at 350-54 (statement of the Pharmaceutical Manufacturers Association); VALUES IN CONFLICT 4, 59-60; Dyck \& Richardson, supra note 23, at 251-55; Shimkin, Scientific Investigations on Man: A Medical Research Worker's Viewpoint, in BIOMEDiCAL ETHICS AND tHE LAw 207, 212 (J. Humber \& R. Almeder eds. 1976). The term "informed" has been viewed as a contradiction in itself. If an experiment is being done, it means the outcome is unknown and thus it is impossible to be informed about it. However, the prospective subject may be informed of potential risks and educated about the results of animal studies. See Values In Conflict 29 (remarks of Francis D. Moore, M.D.). See generally G. AnNas, L. Glantz \& B. KatZ, Informed Consent to Human EXPERIMENTATION (1977).

29. It has been noted that the FDA's current trade secrets policy often results in unnecessary, and thus possibly unethical, duplicative testing. Review Panel on New Drug Regulation, Department of Health, Education and Welfare, Interim Report: An Evaluation of FDA's Trade Secrets and Freedom of Information Policies 36, 39 (Nov. 15, 1976). 
subjects unnecessarily to an experimental drug. ${ }^{30}$ Additionally, tests should be sufficiently well-designed to avoid repetition. ${ }^{31}$ Moreover, unless the FDA is given accurate information, a drug may be marketed under inaccurate claims of effectiveness or with inadequate warnings about its safe use. This not only results in risks to those for whom the drug is prescribed, but it also results in unnecessary exposure to test risks for the test subjects since the results of the test in which they participated will not be reflected in accurate labeling of the drug. ${ }^{32}$

In light of these ethical considerations, human drug testing can be viewed as a "public trust." 33 The concept of public trust has long been used by the legal system to denote a special or higher standard of care on the part of those who serve the public or who otherwise are charged with the maintenance of public assets. ${ }^{34}$ Under this concept, while the responsibility

30. See Review Panel on New Drug Regulation, Department of Health, Education and Welfare, Meeting Transcript 8 (Jan. 25, 1977) (remarks of Allen Astin, Ph.D.). Over-testing can also pose other problems, such as creating additional suffering because of undue delay in the introduction of an important drug. See How SAFE IS SAFE? 110 (remarks of Oliver H. Lowry, M.D.).

31. Review Panel on New Drug Regulation, supra note 30, at 8 (remarks of Allen Astin, Ph.D.).

32. Interagency Coordination in Drug Research and Regulation, Part 3, at 1048 (testimony of Charles D. May, M.D.); Preclinical and Clinical Testing (Part 1), at 67 (testimony of Alexander M. Schmidt, M.D.); How SAFE IS SAFE? 120 (remarks of Peter Barton Hutt). Ph.D.).

33. Review Panel on New Drug Regulation, supra note 30, at 9 (remarks of Allen Astin,

34. For example, the framers of the Constitution were of the view that congressional office holders were occupying an office of public trust. Powell v. McCormick, 395 U.S. 486, 533 n.62 (1969); Tenney v. Brandhove, 341 U.S. 367, 373 (1951); cf. U.S. CoNST. art. VI, \&3. It has been suggested that congressional performance should be measured by this standard. J. KirBY, CONGRESS AND THE PUBLIC TRUST (1970). Similarly, the public trust concept has been used as a standard of performance for nonelected office holders. To provide "for effectuation of the important public interest in securing from public employees an accounting of their public trust," the Supreme Court has held that public employees can be discharged for refusing to answer incriminating questions as long as the dismissal is not the result of the employee's assertion of fifth amendment protections. Lefkowitz v. Cunningham, 431 U.S. 801 (1977); Sanitation Men v. Sanitation Comm'r, 392 U.S. 280, 284 (1968); Gardner v. Broderick, 392 U.S. 273,278 (1968). The Court also has held that public employees can be required to take properly prescribed oaths to support the Constitution "to assure those in positions of public trust [are] willing to commit themselves to live by the constitutional process of our system." Cole v. Richardson, 405 U.S. 676, 684 (1972).

The public trust concept also affects the rights of citizens when assertion of those rights affects the public trust character of public office. Thus the Supreme Court has defended the absolute tort immunity of prosecutors and legislators for actions within the scope of their employment because to hold otherwise would diminish the office holder's ability to fulfill the public trust of his office. Imbler v. Pachtman, 424 U.S. 409, 423-24 (1976); Tenney v. Bradhove, 341 U.S. 367,373 (1951). Similarly, one of the facts that has been used to determine the reasonableness of a government search under the fourth amendment has been the relationship of the reason for the search to the public trust character of the officer conducting the search. The Court in Wyman v. James, 400 U.S. 309, 318 (1971), in upholding the validity of home inspection visits by welfare officials, noted that by such visits "the agency, with tax funds 
for ethical drug investigation is shared by all of the participating entities, ${ }^{35}$ the government, as the initiator of the research, would be the ultimate trustee charged with protecting the individuals involved. ${ }^{36}$ To that end, the government should consider any changes in the existing system that would better protect the individuals involved in clinical testing. It is important to examine the present drug testing system to determine if the public interest is best served by industry sponsorship of drug research. In particular, it is essential to review whether industry's desire to gain maximum profits from drugs creates problems in either the ethical acceptability or the reliability of the present testing system.

\section{The Relationship of the PRofit Motive to RELIABle DRUg Testing}

The hallmark of the present system of drug development is the sponsorship of human drug testing by private concerns whose major motivation is

provided from federal as well as state sources, is fulfilling a public trust." Accord, Lopez v. United States, 373 U.S. 427, 442 (1963) (concurring opinion, Warren, C.J.) (one aspect of reasonableness of a wiretapping search was its purpose to prevent the corruption of "a public servant in the performance of his public trust").

Likewise in areas other than public employment the existence of a public trust has been used to justify special or greater duties on those who hold the trust. For example, in upholding the fairness doctrine, an FCC rule ordering broadcasters to make time available to persons holding viewpoints not expressed during controversial programming, the Supreme Court emphasized that the freedom of action of FCC license holders as protected by the first amendment was more limited than that of newspapers because the scarcity of broadcast frequencies meant that each license had the character of a public trust. Red Lion v. FCC, 395 U.S. 367, 383 (1969). See also Democratic Nat'l Comm. v. FCC, 460 F.2d 891,900 (D.C. Cir.), cert. denied, 409 U.S. 843 (1972). Cf. Rosenbloom v. Metromedia, Inc., 403 U.S. 29, 51 (1971) (opinion of Brennan, J.) ("In an ideal world, the responsibility of press would match the freedom and public trust given it"). For a critique of this concept see Robinson, The FCC and the First Amendment: Observations on Forty Years of Radio and Television Regulation, 52 MINN. L. REV. 67, 151-52 (1967).

The public trust concept also has been used to constrain governmental actions with regard to public water and lands. For example, governmental title to beds beneath waterways and lakes have been considered a public trust for protection of navigation and other public functions. Bonelli Cattle Co. v. Arizona, 414 U.S. 313, 321-22 (1973). Actions inconsistent with this trust have been enjoined. See, e.g. , Illinois Central R.R. v. Illinois, 146 U.S. 387, $452-53$ (1892) (state could not transfer ownership of land reclaimed from Lake Michigan to a private party); State v. Public Service Comm'r, 275 Wis. 112, 81 N.W.2d 71, 73 (1973) (filling a lake bed to develop a recreation area did not violate "the obligations of the trust subject to which the state owns the land"). For a consideration of the extent of the limitations which the public trust concept places and should place on the management of public resources see Sax, The Public Trust Doctrine in Natural Resource Law: Effective Judicial Intervention, $68 \mathrm{MICH}$. L. REv. 471 (1970).

35. Preclinical and Clinical Testing (Part 1), at 347 (statement of the Pharmaceutical Manufacturer's Association).

36. Review Panel on New Drug Regulation, supra note 30, at 9 (remarks of Allen Astin, Ph.D.). 
the hope of realizing a profit from the eventual sale of the drug. ${ }^{37}$ Consideration must be given to how their profit motivation might affect the objectivity and efficiency of the drug testing system.

\section{A. The Role of the Sponsor in Drug Research.}

Conventional economic thought holds that a private corporation's estimate of the anticipated profit from a new product takes into account possible social or external damage caused by the product to the extent that the public's ill will might decrease sales ${ }^{38}$ or that its profits may be diminished by tort actions against the company for injuries caused by the product. ${ }^{39}$ Decisions within the pharmaceutical industry concerning the research and development of new drugs appear to fit this pattern. The sponsor's future financial planning with regard to a new drug depends on an accurate appraisal of the drug's therapeutic value, ${ }^{40}$ including any dangers which might lead to tort liability. ${ }^{41}$ Additionally, the anticipated cost of developing a drug includes the expense of further testing that may be required if the FDA finds test data to be inaccurate or inadequate..$^{42}$ For these reasons, there is a substantial corporate interest in obtaining accurate information. Moreover, there is a strong ethically motivated desire among drug sponsors to turn out effective products, ${ }^{43}$ and this is only possible when production is preceded by thorough and valid research.

Nevertheless, because of the potential for profit from a successful drug, it is claimed that a pharmaceutical firm's view of information about its drugs may be colored by its natural desire to turn out commercially successful compounds ${ }^{44}$ and this bias may result in the firm interpreting data more favorably than would independent observers. ${ }^{45} \mathrm{Dr}$. Louis Lasagna reports

37. How SAFE is SAFE? 174 (remarks of Phillip Handler, M.D.).

38. See Katz, The Function of Tort Liability in Technology Assessment, 38 U. CIN. L. REV. 587,592 (1969).

39. Id. 593. In addition to tort law, the pervasive development of property and contract law, supplemented by such related legal areas as tax, patent law, copyright law, antitrust and zoning law all affect a corporation's assessment of the risk and benefit of the proposed action. National Academy of Sciences, Technology: Processes of Assessment and Choice 25 (1969).

40. Examination of the Pharmaceutical Industry (Part 5), at 2325 (testimony of Leon Goldberg, M.D.).

41. How SAFE is SAfE? 138 (remarks of W. Clarke Wescoe, M.D.).

42. See 21 U.S.C. § 355(d) (1970); see notes 5-20 supra and accompanying text.

43. See text accompanying notes $57-58$ infra.

44. Examination of the cyclamate literature, for example, indicates that studies sponsored by cyclamate manufacturers generally showed that cyclamates were acceptably safe, while, in contrast, studies sponsored by the Sugar Research Foundation tended to show that cyclamates were harmful. How SAFE is SAFE? 221 (remarks of Samuel S. Epstein, M.D.).

45. Interagency Coordination in Drug Research and Regulation, Part 4, at 1614 (professional paper by Louis Lasagna, M.D.). More generally, Consumers Union reports that its tests of all types of consumer products have demonstrated that "with the best of intentions, the manufac- 
that he has observed such instances in scientific meetings, in personal discussions and in the sometimes acrimonious exchanges which follow evaluation of a firm's product by outside bodies such as the American Medical Association's Council on Drugs or the Medical Letter on Drugs and Therapeutics. ${ }^{46}$

Thus, the sponsor's motivation to obtain accurate information should not be considered sufficient to ensure the objectivity or reliability of test results. In fact, as presently constituted, the relationship between the sponsor and its researchers may have the effect of subtly biasing the results of studies in favor of drugs being tested, thereby undermining the accuracy of data submitted to the FDA.

\section{B. The Relationship Between Sponsors and Researchers.}

Most pharmaceutical companies contract out their clinical research on humans to university-affiliated hospitals. ${ }^{47}$ Although some companies also contract out their preclinical animal tests, ${ }^{48}$ this research usually can be done by private pharmaceutical firms. The contractual relationship between the sponsor and the physician doing clinical research varies, but it usually includes reimbursement for expenses incurred, ${ }^{49}$ and it sometimes includes payment for services rendered. ${ }^{50}$

The fact that the testing physician or clinical laboratory receives financial support from the drug's sponsor has been viewed as creating a conflict of interest. ${ }^{51}$ Some observers believe that a clinical researcher who is

turer of a product may be unable to take view of his own handiwork that is objective enough to reveal the product's weaknesses." Drug Safety, 28 Consumer REPORTS 134 (Mar. 1963).

46. Interagency Coordination in Drug Research and Regulation, Part 4, at 1614-15 (professional paper by Louis Lasagna, M.D.). Dr. Lasagna further reported regarding tests he had done of several proprietary analgesic preparations:

The reaction was extraordinarily revealing: the firms which stood to gain by the article embraced us with warmth; the others acted as though we were lepers. . . . It is difficult to believe that the same article could be both a "fine contribution" and an "atrocity!" It seems more likely that one important criteria for evaluating a medical article disregards the validity of its contents, but look to its effects on corporate Id. earnings.

47. Preclinical and Clinical Testing (Part 1), at 343 '(statement of the Pharmaceutical Manufacturers Association); How SAFE IS SAFE? 135 (remarks of Peter Barton Hutt). The need for outside assistance arises because the pharmaceutical firms do not have access to human subjects on whom the drugs can be tested. B. BARBER, supra note 26, at 88.

48. Hearings on Preclinical and Clinical Testing by the Pharmaceutical Industry Before the Subcomm. on Health of the Senate Labor \& Public Welfare Comm., 94th Cong., 2nd Sess., Part 3, at 27, 724 (1976).

49. Interagency Coordination in Drug Research and Regulation, Part 4, at 1601.

50. M. MINTZ, BY PRESCRIPTION ONLY 292 (1956). Sponsors may have to pay clinical investigators because the job can be dull and time-consuming. Competitive Problems in the Drug Industry (Part 10), at 3986 (testimony of George Nichols, M.D.).

51. Competitive Problems in the Drug Industry (Part 10), at 3920 (testimony of William Bean, M.D.); id. at 3985 (testimony of George Nichols, M.D.). See generally B. BARBER, supra 
beholden to a sponsor for financial support cannot make a detached observation concerning the cause and significance of physical effects of the experimental drug, ${ }^{52}$ and that in making subjective judgments, a researcher will be at least unconsciously influenced by the fact that a drug company is paying for the research and hoping for favorable results. ${ }^{53}$

The problem of objectivity that is inherent in the relationship between the sponsor and the investigator has been recognized for many years. In 1961, it was observed that the company's influence over researchers came not as much from financial payment as from personal contact.

Having spent some 6 years in the business of influencing clinical investigators, I can assure you that objectivity can be destroyed more frequently and more effectively by the soft sell than by the bribe . . . . A paternalistic attitude toward the detail man who is a "nice fellow" and who requests the "study"; the positive response to the medical director "who traveled all the way from New York" to "consult" the "investigator"; the wish to be an "investigator" and perhaps to be invited to give a paper at a "symposium"; the fantasy of prestige and of the respect of the medical community; the certain knowledge that no one ever won a Nobel Prize by publishing a negative paper about an obscure drug; the fantasy of the "pioneer" who blazes the trail to the discovery of a new drug - these are only a few examples of the really potent influences which determine objectivity in drug studies. ${ }^{54}$

There are other ways in which the objectivity of data may be compromised. When a sponsor is unable to obtain its first choice of an investigator, it is possible that the clinician who finally accepts the job may do so because he favored the drug in the first place. ${ }^{55}$ In addition, the reliability of data from either animal or human testing may be affected if investigators find they are operating under rigid deadlines. If the sponsor desires to obtain results at the earliest possible moment to recover expeditiously its investment, it may

note 26, at 88-89; M. MiNTZ, supra note 50, at 292-304c.

52. How SAFE IS SAFE? 135 (remarks of Oliver H. Lowry, M.D.). Similarly, it has been asserted that drug industry supported educational materials, while accurate, contain a "systematic bias . . . tilted in the direction of therapeutic enthusiasm." Crout, Drug Industry Influence Poses Threat to Medical Education, 12 TRIAL 31 (1976).

53. Competitive Problems in the Drug Industry (Part 10), at 3921 (testimony of William Bean, M.D.).

54. M. MinTZ, supra note 50, at 302; see The Pharmaceutical Persuaders-The Industry, The Doctor, and The Clinical Trial, LANCET, Aug. 19, 1961, at 421, 421-23. The pharmaceutical firm also can compromise less subtly the objectivity of a researcher by offering to do statistical workups for the researcher or by offering to write his paper. Id. 422; see B. BARBER, supra note 26 , at 23-24.

55. How SAFE is SAFE? 135 (remarks of Oliver H. Lowry, M.D.); Comment, The Food and Drug Administration: Law, Science and Politics in the Evaluation and Control of New Drug Technology, 67 Nw. U.L. Rev. 858, 882-83 (1973). Contra, How SAFE IS SAFE? 135 (remarks of W. Clarke Wescoe, M.D.). 
communicate a sense of urgency to the researcher. Such time pressures may cause researchers to make errors in their analyses of data. ${ }^{56}$

While acknowledging the potential for misleading results under the present system, scientists assert that the professionalism of those involved provides a substantial guarantee of reliability. ${ }^{57}$ One physician described the influence of professionalism on the drug testing process as follows:

[T] here are going to be some people who will be found in any community who might bow to temptation, but . . . the vast majority of the drug testing being done now is being done in academic centers and with high standards regardless of who sponsors the testing . . . . Testing is being done by people who have their academic reputations on the line, not simply support for their future studies. The results they obtain will eventually be published in a reputable journal-the careers of the investigators are at stake. Thus there are check systems within the system which will guarantee you that good testing can be done. ${ }^{58}$

Undoubtedly, professionalism is an important factor in promoting accurate information, but recent events indicate that its effects must not be overestimated. Caution is necessary because fraud in research exists and apparently is rising. ${ }^{59}$ Moreover, scientists have begun to examine critically the adverse impact that the sponsorship of research might have on the integrity of the resulting data. ${ }^{60}$

The criminal penalties for submission of fraudulent data to the FDA ${ }^{61}$ reflect society's belief that government oversight is necessary. The FDA's policy of checking test results submitted by sponsors similarly reflects this concern. ${ }^{62}$ The important questions are whether such checking is, or can be, sufficient to verify the submitted data and whether the criminal penalties are, or can be, sufficient incentive to sponsors to furnish reliable data. To answer these questions, it is important to assess the extent to which problems have arisen with regard to the reliability of data.

56. New York Acad. of Medicine, supra note 24, at 143; Interagency Coordination in Drug Research and Regulation, Part 4, at 1601.

57. How SAFE is SAFE? 136, 200 (remarks of W. Clarke Wescoe, M.D.); cf. GenERAL Accounting Office, Federal Control of New Drug Testing is Not Adequately Protecting Human Test Subjects AND the Public 28 (1976).

58. Examination of the Pharmaceutical Industry (Part 5), at 2301-02 (testimony of Kenneth Melmon, M.D.).

59. Rensberger, Fraud in Research is a Rising Problem in Science, N.Y. Times, Jan. 23, 1977, at 1, cols. 1-3, at 44, cols. 3-6; Vonder Haar \& Miller, Warning: Your Prescription May be Dangerous to Health, New YORK, May 16, 1977, at 54; Violating Nature, TIME, Mar. 14, 1977, at 54 .

60. Horowitz, Science, Sin and Sponsorship, ATLANTIC, Mar. 1977, at 99, 101; Trippett, Science: No Longer a Sacred Cow, Time, Mar. 7, 1977, at 72-73.

61. 18 U.S.C. \& 1001 (1970).

62. How SAFE is SAFE? 172-74 (remarks of Phillip Handler, M.D.); see note 18 supra and accompanying text. 


\section{Misleading or Fraudulent Industry-Generated Research.}

The FDA has found that several animal and clinical test results have been fabricated or otherwise made misleading by sponsors or by toxicology laboratories working for sponsors. ${ }^{63}$ Recent incidents have been sufficiently serious for FDA officials to call for a re-examination of the general reliability of industry animal test submissions. ${ }^{64}$

In early 1976, the FDA raised questions regarding the integrity of animal data submitted to it by G.D. Searle Company in support of the drugs Flagyl and Aldactone. ${ }^{65}$ To determine the seriousness of the discrepancies in Searle's data, the FDA formed a task force which studied the data in question as well as data submitted in support of other Searle drug applications. On-site investigations were conducted of Searle laboratories. ${ }^{66} \mathrm{Based}$ on this investigation, the FDA reported to a Senate committee that

Searle made a number of deliberate decisions which seemingly were calculated to minimize the chances of discovering toxicity and/or to allay FDA concern . . . .

In addition, Searle made other decisions which may have been inadvertent or unintentional which produced similar results. ${ }^{67}$

On this record, the FDA.recommended to the Department of Justice that grand jury proceedings be instituted to determine if Searle had violated the Federal Food, Drug and Cosmetic Act (FDCA). ${ }^{68}$

Additional investigations indicated that at least one other major pharmaceutical manufacturer had the same sort of serious deficiencies in its animal testing procedures, ${ }^{69}$ that three other companies withheld adverse animal data from the agency, ${ }^{70}$ and that several contract animal testing laboratories had problems similar to those at Searle. ${ }^{71}$ Responding to a statement that the situation uncovered by the FDA is "serious and grave," the FDA Commissioner Alexander Schmidt replied:

I would agree with that characterization . . . .

63. See text accompanying notes $65-76$ infra.

64. Preclinical and Clinical Testing (Part 2), at 6-7.

65. Id. 5-6. See generally Vonder Haar \& Miller, supra note 59, at 46-52.

66. Vonder Haar \& Miller, supra note 59, at 57-58.

67. Hearings on Preclinical and Clinical Testing by the Pharmaceutical Industry, supra note 48 , at 25,27 . In addition, animal studies done by a Searle contractor, Hazelton Laboratories, were also found to have serious flaws in research design and performance. Id. 27, 724.

68. Id. 724.

69. Id. 725.

70. Preclinical and Clinical Testing (Part 1), at 43-44.

71. Hearings on Preclinical and Clinical Testing by the Pharmaceutical Industry, supra note 48 , Part 3 , at 725 . 
It is certainly more widespread than I would have guessed. I think it represents an area in which we have never been active in regulating, and now clearly we must be. ${ }^{72}$

Similar problems were discovered in the early 1960 s with respect to clinical testing. In 1963, two clinical researchers reported that they were approached by a pharmaceutical sponsor whose offer to finance research was predicated upon a return promise that the test results would be favorable. ${ }^{73}$ In 1964, a clinical researcher pleaded nolo contendere to an indictment charging that he willfully submitted fictitious reports of clinical studies in support of five separate new drug applications. ${ }^{74}$ Similarly, from 1963 to 1965 three pharmaceutical companies and several of their employees were convicted of, or pleaded nolo contendere to, charges that they had fraudulently withheld from the FDA information adverse to their drug applications. ${ }^{75}$ All three of the drugs that were involved, MER-29 by Richardson Merrell, Inc., Dornwell by Wallace and Tiernan, and Flexin by McNeil Laboratories, were approved by the FDA in ignorance of the withheld information, and subsequently were prescribed for large numbers of patients. ${ }^{76}$

These clinical incidents predate the 1962 Amendments to the FDCA, which included provisions that require the registration of drug manufacturers, allow for the inspection of drug plants, and impose more rigid controls over the manufacture and approval of drugs. ${ }^{77}$ Although comparable incidents have not been discovered since, the FDA apparently believes that problems still exist in the field of clinical research:

We have looked more at clinical research, and . . . have not found the kinds of very serious errors . . . in clinical research which we found in some of the animal toxicology research . . . . [Nevertheless] faults in protocol design can be found in both clinical and animal research. Inadequate training of research workers is to be found in both, and sometimes improper data handling is to be found in both clinical research and animal toxicology research. ${ }^{78}$

The FDA believes that potentially the problems are more serious in experiments involving animals than in those conducted on humans. Clinical

72. Id.

73. Interagency Coordination in Drug Research and Regulation Part 3, at 1018.

74. Interagency Coordination in Drug Research and Regulation, Part 6, at 3197-98. See generally M. MiNTZ, supra note 50, at 328-36.

75. See generally M. MinTZ, supra note 50, at 17-32, 36q, 230-47; Greenberg, How Safe Are Your Drugs, Science Digest, June 1975, at 54.

76. Flexin was used by 3 million people, Dornwell by 160,000 and MER-29 by 418,000 . M. MiNTZ, supra note 50 , at $20,27,246$.

77. 21 U.S.C. $\S \S 301-392$ (1970), as amended by Act of Oct. 10, 1962, Pub. L. No. 87-781, 76 Stat. 780. See S. Rep. No. 1744, 87th Cong., 2d Sess. 8 (1962).

78. Preclinical and Clinical Testing (Part 2), at 46-47 (testimony of Alexander M. Schmidt, M.D.). 
research often is conducted in universities and the results may be published in the medical literature. Animal testing is conducted by the sponsor or a contract laboratory and is not as susceptible to peer scrutiny. ${ }^{79}$ The FDA also requires the submission of raw data for clinical research, but not for animal studies. ${ }^{80}$

For both animal and clinical research, the FDA thinks that the problems which it finds result primarily from poor and sloppy procedures, rather than from deliberate distortions of data. ${ }^{81}$ However, the effects of the two sources of error are the same; both prevent the FDA from obtaining accurate information upon which to base its decisions. ${ }^{82}$

\section{PROPOSALS FOR IMPROVING THE RELIABILITY OF DATA}

\section{A. FDA Efforts.}

Until recently, the FDA's ability to verify the animal and clinical studies submitted to it was limited. The agency conducted no testing of its own, ${ }^{83}$ and it inspected only a small number of laboratories and only about one percent of the 12,000 active clinical investigators in order to verify raw data. ${ }^{84}$ However, the agency expects to increase significantly its surveillance efforts, primarily of preclinical laboratories and clinical investigators. After the serious discrepancies were discovered in the Searle animal data, ${ }^{85}$ Congress authorized the FDA to hire and train 606 additional persons to be used in research verification. ${ }^{86}$ With these personnel, the FDA estimates that it will be able each year to inspect half of the laboratories used in animal testing, half of the sponsors of clinical studies and about three percent of the active clinical investigators. ${ }^{87}$

79. Id. 46 .

80. Id.

81. Preclinical and Clinical Testing (Part 1), at 12 (testimony of Alexander M. Schmidt, M.D.).

82. Preclinical and Clinical Testing (Part 2), at 83 (statement of Alexander M. Schmidt, M.D.). See also Ladimer, Quackery and the Consumer-Responsibility of the Medical Profession, 18 Food DRUG Cosm. L.J. 436, 448 (1963).

83. Preclinical and Clinical Testing (Part 1), at 9 (testimony of Alexander M. Schmidt, M.D.).

84. Id. 10 .

85. See notes 65-68 supra and accompanying text.

86. Letter from' Sherwin Gardner, Acting FDA Commissioner, to Jamie L. Whitten, Member of the House of Representatives (Jan. 3, 1977) (Food and Drug Administration 1977 Budget Amendment).

87. During 1977, the FDA was to inspect at least 80 of the 550 laboratories that conduct animal testing, 85 of the research sponsors and 165 of the 12,000 clinical investigators. Statement by Sherwin Gardner, Acting FDA Commissioner, Subcomm. on Health and Scientific Research of the Senate Comm. on Human Resources and Subcomm. on Administrative Practice and Procedure of the Senate Comm. on the Judiciary, Mar. 10, 1977, at 7, 11. 
To facilitate these inspections, the FDA is considering imposing uniform standards for research procedures. For example, in the area of animal studies, it has proposed regulations delineating Good Laboratory Practice for Nonclinical Laboratory Studies. ${ }^{88}$ The proposed regulations, which are analogous to the agency's good manufacturing practice regulations, ${ }^{89}$ set standards for several aspects of animal testing: animal husbandry practices, training of personnel, recording and handling data, administration of the test chemical, recordkeeping, and the reporting of results to management. ${ }^{90}$ In addition, the proposed regulations require testing laboratories to establish quality control units. Such units would be responsible for assuring that specific written procedures and protocols are developed for each animal study, for monitoring the studies to assure compliance with those procedures and protocols, and for certifying to management that the study was conducted in accordance with FDA regulations..$^{91}$

The FDA's newly expanded inspection staff would also conduct inspections of animal laboratories in order to determine whether they are complying with the proposed animal testing regulations..$^{92}$ These inspections would be similar to those of drug manufacturing facilities, which assess whether the facilities are in compliance with the FDA's manufacturing practice regulations. ${ }^{93}$ Since the manufacturing inspections have improved the quality of the drug manufacturing process, the FDA believes this program would likewise improve the quality of the animal research. ${ }^{94}$

These proposals have several advantages. The guidelines would help eliminate inefficiency by the sponsor and thus minimize the possibility that test subjects would be exposed unnecessarily to an unapproved drug. The standards also would provide the FDA with a basis for determining whether the research was conducted in a procedurally sound manner, and they would help to prevent the "sloppy science" of which the FDA currently complains. ${ }^{95}$ Further, assuring procedural regularity to some extent would help prevent deliberate distortions of data, since methodological errors that are discovered may serve as a clue to the FDA to search for more serious problems.

While the FDA's verification program promises to increase sponsors' incentive to submit accurate data to the agency, one problem in data reliability nonetheless may remain. The possibility would still exist that data

88. 41 Fed. Reg. 51206 (1976).

89. Preclinical and Clinical Testing (Part 2), at 98.

90. Id. 99.

91. Id.

92. Id.

93. Id. 100 .

94. Id.

95. See text accompanying notes 81-82 supra. 
submitted to the FDA could be unintentionally and subtly biased. Whether FDA reviewers are capable of detecting subtle biases in the data they review appears to be an open question. One FDA official, Dr. Frances O. Kelsey, believes that subtle shadings in reporting and evaluating data are beyond the agency's ability to detect. ${ }^{96}$ Recently, however, the Commissioner of the FDA has voiced the belief that FDA reviewers are "fully able to detect inaccurate or self-serving analyses or conclusions." 97 Despite this debate and whatever the absolute capabilities of FDA reviewers, it seems clear that the sheer volume of the workload of FDA investigators may tax their ability to detect errors introduced by bias. ${ }^{98}$

\section{B. Further Modifications in the Present Systems Designed to Improve the Accuracy of Experimental Data.}

1. Clinical Research Standards. It has been suggested that the only means of policing bias in research is to insist on strict adherence to properly designed research standards:

[A]n approach to the problem of lack of objectivity in drug studies through the prohibition of one or more of the thousands of incentives to bias is naive and misdirected . . . . Our attention should center on the signs of objectivity in drug studies . . . . Objectivity and/or its absence are inherent in the design of the study, the manner of its execution and the validity of the conclusions drawn from it . . . The objective examination of an adequately detailed report of a study in the light of well-established and accepted standards of scientific methodology forms the best instrument for evaluating objectivity. ${ }^{99}$

Under the present system of clinical testing, the pharmaceutical firm and the clinical investigator conducting the research design the protocols for each of the clinical studies. ${ }^{100}$ For several years, the FDA has been in the process of developing a series of guidelines that are to be given to sponsors to delineate, for different classes of drugs, what the agency considers to be the important considerations in clinical studies. ${ }^{101}$ The FDA does not consider these guidelines to be formal protocols that must be rigidly followed, but it expects that adherence to the guidelines will enable researchers to avoid wasteful, poorly designed, unacceptable testing. ${ }^{102}$

96. Comment, supra note 55 , at 881 .

97. Preclinical and Clinical Testing (Part 1), at 9.

98. See note 18 supra and accompanying text.

99. Examination of the Pharmaceutical Industry (Part S), at 2290 (letter from A. Dale Console, M.D., to Senator Hubert H. Humphrey).

100. American Enterprise Institute for Public Policy Research, New Drugs Pending Legislation, Legislative ANALYSIS No. 13, 94th CoNG. 37 (1976).

101. Review Panel on New Drug Regulation, Department of Health, Education and Welfare, Interim Report: Preclinical and Clinical Guidelines at the Bureau of Drugs of the Food and Drug Administration (Feb. 28, 1977).

102. Id. 
In addition to these voluntary guidelines, greater supervision by the FDA over clinical studies has been proposed as a means for uniformly improving the quality of data. One means of increasing the agency's supervisory role would be to institute meetings with the sponsor at critical times during the investigational process. ${ }^{103}$ There also have been suggestions that the FDA be given greater authority in this area. The agency could, for example, be given additional authority to approve individual protocols before clinical studies are initiated ${ }^{104}$ and to approve sequentially each step of the investigational process before the next step could be commenced. ${ }^{105}$

These proposals should help improve the overall quality of clinical data ${ }^{106}$ because to the extent that they would standardize research practices, or at least identify the practices used for a particular experiment, the FDA could more easily monitor the proper implementation of a study. ${ }^{107}$ However, there are important disadvantages that may offset these advantages. Standardizing research may discourage innovation and thereby decrease the availability of new drugs. ${ }^{108}$ Additionally, the proposals may slow the drug development process, which of course, would have the same effect. ${ }^{109}$ The latter consequence has been stressed by industry research scientists:

[W]e believe it would take substantially longer for important new drugs to be made broadly available for the treatment of diseases, if the research and development process in this country has to suffer yet another quantum increase in the level of formalized regulatory involvement during the exquisitely sensitive early stages of discovery and clinical validation. Furthermore, although we strongly endorse the value of consulting FDA on program plans . . . we view with great concern the present proposal to make this a highly structured procedure, culminating in formal approval by the agency. ${ }^{110}$

The establishment and monitoring of standards for animal and clinical studies appears to be a useful first step in improving the quality of data that are submitted to the FDA. But it is important that such guidelines not be so rigid as to create either a research atmosphere that discourages the development of new drugs or to foster further delays in the process for drug approval.

2. Changes in Enforcement Policies. Increasing the FDA's enforcement efforts is another way to improve the reliability of information

103. It has been recommended that conferences between the FDA and the sponsor be optional at the end of the first phase of clinical studies and be mandatory prior to initiation of large scale clinical trials. Review Panel on New Drug Regulation, supra note 16, at 4.

104. See S. 2697, 94th Cong., 1st Sess. § 404(d)(2) (1975).

105. Id. \& 404(b)(2).

106. See notes 101-05 supra and accompanying text.

107. See notes 88-94 supra and accompanying text.

108. Review Panel on New Drug Regulation, supra note 101, at 44.

109. AMERICAN ENTERPRISE INSTITUTE FOR PUBLIC POLICY RESEARCH, supra note 100, at 42.

110. Id. 
submitted to the agency. Under the FDCA if the agency receives inaccurate or misleading data, it may use any of the following sanctions: an information letter advising a firm or person of violations of law and regulations; ;11 a regulatory letter which cites specific violations, sets a deadline for a response regarding corrective actions and advises that administrative or legal action will be taken if corrective action is not undertaken; ${ }^{112}$ disqualification of clinical investigators from eligibility to receive investigational new drugs if they repeatedly or deliberately violate the FDCA or its regulations; ${ }^{113}$ termination of a sponsor's IND; ${ }^{114}$ disapproval of an NDA; ;15 or withdrawal of a marketed drug. ${ }^{116}$ The following legal actions can be initiated through the Department of Justice: prosecuting an individual for use of the mails to submit fraudulent data to the government; ${ }^{117}$ enjoining individuals or firms from violation of the FDCA or regulations; ${ }^{118}$ seizing any drug which is adulterated or misbranded when introduced into, or while it is in, interstate commerce. ${ }^{119}$

A 1976 Government Accounting Office (GAO) investigation reported that, according to the FDA, "in most cases, clinical investigators inspected were not fully complying with federal law or agency regulations and that pharmaceutical sponsors were not adequately monitoring their clinical investigators." 120 Nevertheless, the GAO found that the FDA made only "limited use" of its potential enforcement actions. ${ }^{121}$ The GAO noted that, since 1962, the FDA has recommended that the Department of Justice initiate only two prosecutions for fraud, that it had disqualified only twenty clinical investigators and that the FDA's Bureau of Drugs had never issued a regulatory letter concerning noncompliance with testing regulations. ${ }^{122}$ However, the FDA has sent information letters to those found not in compliance after an FDA investigation. ${ }^{123}$

111. Federal Control of New Drug Testing 21.

112. Preclinical and Clinical Testing (Part 2), at 369.

113. 21 C.F.R. $\$ 312.1(c)(1)-(2)(1977)$.

114. Id. § $312.1(\mathrm{~d})$.

115. 21 U.S.C. § 355(d) (1970); 21 C.F.R. § 314.111 (1977)

116. 21 U.S.C. $\$ 355(\mathrm{e})$ (Supp. V 1975); 21 C.F.R. $\$ 314.115$ (1977).

117. 18 U.S.C. $\S 1001$ (1970).

118. Id. §332(a).

119. 21 U.S.C.A. § 334 (West Supp. 1977). See generally CIBA Corp. v. Weinberger, 412 U.S. 640,644 (1973).

120. Federal Control of New Drug Testing 11; Preclinical and Clinical Testing (Part 2), at 365. The GAO indicated that 1972 survey by the FDA revealed that seventy-four percent of the investigators sampled failed to comply with one or more requirements of the law and regulations. Id.

121. Federal Control of New Drug Testing 11. The GaO notes that the FDA does not disagree with the findings but does dispute some of the recommendations. Id. 27. See also Preclinical and Clinical Testing (Part 2), at 360-77.

122. Preclinical and Clinical Testing (Part 2), at 369.

123. Federal Control of New Drug Testing 21-22. 
The GAO conclusion that the FDA has been lax in its enforcement efforts may be somewhat overstated because many of the violations uncovered may not have been serious enough to warrant FDA action. Nevertheless, as the GAO indicates, lesser administrative sanctions were available to the agency for the more minor infractions. Moreover, additional evidence tends to corroborate the GAO's belief that the FDA has not been an efficient enforcer of its rules. On several occasions between 1971 and 1974, the FDA failed to deal in a timely fashion with enforcement recommendations, apparently losing them somewhere in its bureaucracy. ${ }^{124}$ For example, in April 1970, the FDA discovered that a nine-month period had elapsed between the discovery of unacceptable adverse effects in animals by Lederle Laboratory employees and the reporting of these results to the FDA. After conducting three inspections of Lederle in 1971, an FDA inspection team recommended that the company not be prosecuted because it had found Lederle management had promptly informed the FDA of the test results upon learning of them from employees who had been tardy in their reporting. The FDA concluded that the failure of Lederle employees to inform management was a "question of scientific judgment." 125 The inspection team recommended to the Director of Bureau of Drugs of the FDA that a letter of warning be sent to Lederle recommending management changes to prevent further delays in providing information of this sort to the FDA. Four years later, the FDA discovered that the memorandum containing this recommendation had never reached the Bureau Director's office. ${ }^{126} \mathrm{~A}$ similar experience occurred with the drug Slow-K. In that case, a recommendation that criminal action be considered against Ciba-Geigy for withholding information was not acted upon between 1972 and 1974 because of a bureaucratic misunderstanding as to who would refer the case to the Department of Justice. ${ }^{127}$

Based on his observations of the FDA compliance efforts, a GAO official concluded that, because of lax enforcement, clinical researchers could feel unconstrained by FDA regulations concerning the quality of their research. ${ }^{128}$ Thus, the adoption of an active and aggressive enforcement posture on the part of the agency clearly would improve the FDA's efforts to improve the reliability of data.

The FDA, however, disagrees. Commenting upon the GAO recommendations, it observed:

124. See Preclinical and Clinical Testing (Part 1), at 133-40.

125. Id. 138.

126. Id. 139.

127. Id. 134-35.

128. Preclinical and Clinical Testing (Part 2), at 347-48. 
GAO assumes an adversarial relationship between FDA and the research community. The goals of science and medicine and of FDA regulation are the same: ethical research, scientifically valid and useful research, research protecting and benefiting both the subjects and patients generally. Achieving these objectives requires both clear exposition of FDA policies to encourage understanding and compliance and judicious application of sanctions in those situations where clearly improper behavior is found. For the FDA to approach researchers as though their only incentive to comply is threat of FDA action, however, demeans the ethical and professional standards of these persons and is unjustified by the evidence. Moreover, a hostile FDA might produce a reluctance to cooperate with the Agency, or worse, a disincentive for research itself. ${ }^{129}$

The FDA is charged with the responsibility to enforce compliance with the FDCA and the regulations it promulgates. At times, that responsibility will require the agency to assume an adversarial posture with respect to drug producers. The issue is not whether the FDA should be adversarial, but how to balance its compliance and educational efforts. In light of the GAO study and other examples cited above, it appears that the FDA's efforts have insufficiently stressed its enforcement role.

Yet, even if the FDA did increase its enforcement efforts, the enormous number of experiments being conducted and the relatively small size of the FDA enforcement staff might still make detection of violations difficult. The Department of the Interior solved a similar problem with respect to coal mine inspections by singling out those coal mines whose safety performance records were the worst and concentrating its enforcement efforts on them. ${ }^{130}$ Senator Richard Schweiker has proposed that the FDA implement a similar plan:

We can come up with similar proposals that in spot checking the pharmaceutical companies . . . we begin to establish some kind of scientific reliability factor. When a company falls into a questionable status . . . we escalate the procedures and the inspections on all the products. ${ }^{131}$

Senator Gaylord Nelson has suggested the cost of the additional monitoring might be assessed to the drug firm. ${ }^{132}$

A formal system of selective review would be the best use of the FDA's limited enforcement resources. In addition, such a system would reward

129. Federal Control of New Drug Testing 28.

130. Preclinical and Clinical Testing (Part 1), at 69.

131. Id.

132. Preclinical and Clinical Testing (Part 2), at 159. The FDA has stated that it already informally distinguishes between companies it perceives are doing a good job and those that are not, because medical officers more meticulously check the data from suspect companies. Preclinical and Clinical Testing (Part 1), at 70. 
companies that meet FDA standards. Companies will know that compliance will free them from time-consuming inspections ${ }^{133}$ and that competitors will not gain an advantage over them by engaging in improper conduct. If such a system is combined with the FDA's present plans to check data randomly, ${ }^{134}$ this proposal would seem to be useful to the agency.

\section{Alternatives to the Present System Designed to Improve the Accuracy of Experimental Data.}

While the preceding proposals could be implemented without considerable change in the present system of drug testing, consideration also has been given to proposals that would dramatically alter that system. These proposals include establishing a third-party testing apparatus to either verify industry test results or to replace industry testing altogether.

1. Limited Third-Party Testing. Although strengthening the present FDA oversight of drug testing might improve both the incentive to submit accurate information to the FDA and the agency's ability to check the accuracy of the information submitted, the FDA would still lack means to verify whether the same test results could be arrived at independently. Recently, the FDA decided that an objective, competent third-party was needed to verify certain aspects of animal test data submitted by the G.D. Searle Company in support of Aspartame, an artificial sweetener. ${ }^{135}$ The FDA informed Searle that certain of the Aspartame studies had to be verified utilizing a review mechanism which operated independently of, but was funded by, Searle or other private sources. ${ }^{136}$ The FDA required that the authentication review be a matter of public record because the ultimate conclusion with regard to Aspartame would be sharply scrutinized and therefore had to be "the product of sound, open, and thus credible procedure." 137

If the procedure followed with regard to Aspartame were formalized and continued, the FDA could seek independent testing of animal data submitted to it whenever such data were conflicting or insufficient, a role which has been urged for the agency. ${ }^{138}$ Since the FDA would have access

133. Id. 69.

134. See text accompanying notes 86-87 supra.

135. Statement by Sherwin Gardner, Acting Commissioner, FDA, Before the Senate Select Comm. on Small Business, at Appendix G, 3 (Jan. 13, 1977). A current legislative proposal would explicitly authorize limited third-party testing for the FDA. H.R. 11617, 94th Cong., 2d Sess. $\S 476$ (1976). The purpose of the legislation is to allow health officials to study the relative efficacy of drugs that are used to treat the same disease. However, it is possible to interpret the proposal as also authorizing testing for purposes of verification.

136. Statement by Sherwin Gardner, supra note 135.

137. Id. at Appendix $\mathrm{G}, 4$.

138. H. Dowling, Medicines for Man: The Development, Regulation and Use of PRESCRIPTION DRUGS 250-51 (1970); Dowling, The Pharmaceutical Industry and the Doctor, 264 
to independent test results from persons with no ties to the sponsor, there would be added incentive for sponsors both to avoid deliberate distortions of data and to try to minimize any distortions arising from possible bias. If the expense of such testing were assessed to the company, as was done with Aspartame, there would be a minimal federal expenditure involved.

The FDA could in addition, or alternatively, use a third-party testing mechanism to spot check the results of animal experimentation by reconducting a sample of studies. ${ }^{139}$ Such spot checking would be an incentive for sponsors to obtain accurate results, since there would be a greater probability that inaccurate data would be discovered.

However, there are problems with the spot checking approach. Given the large number of animal experiments that are conducted at any one time, an elaborate system of spot checking would be required to discover a significant amount of inaccuracies. In addition, while the FDA has charged a sponsor for the expense of additional independent testing in an instance where the sponsor may have submitted inaccurate data, ${ }^{140}$ it is questionable whether it would be proper to assess sponsors the cost of random checking where they have not produced inaccurate data in the past.

Despite these disadvantages, spot checking of animal studies may be useful. The program could be fairly small, operated at a reasonable cost to the government or industry, and because sponsors would not know beforehand if their tests would be checked, it could still have the effect of creating an incentive to conduct accurate tests. ${ }^{141}$ Moreover, since there would be no indication that the data under examination were faulty, the validation tests could be conducted while studies of the drug continued. The program therefore would not slow the drug development process.

Use of limited third-party testing for clinical studies presents more difficult problems. Most importantly, there is a serious ethical problem in having research subjects volunteer to undergo risks to obtain data that the FDA may already have in accurate form. The social benefit that normally justifies human testing is not as compelling in such an instance. In addition, if third-party testing were used to verify clinical data, the difficulty would arise of obtaining test subjects in a second test who have virtually the same

N.E. J. MEDICINE 75, 77 (1961). Although it has been proposed that the FDA undertake the testing, such involvement seems improper for the agency since it is to judge the results of the research. See Interagency Coordination in Drug Research and Regulation, Part 4, at 1620 (letter from Heber W. Youngken, Jr., M.D., to Senator Hubert H. Humphrey (Oct. 23, 1963)).

139. Review Panel on New Drug Regulation, supra note 30, at 14 (remarks of David Rall, M.D., Ph.D.).

140. See notes $135-37$ supra and accompanying text.

141. The size of the program should correspond to the likelihood of a sponsor submitting misleading or inaccurate data. Anything but a token spot checking effort should have the desired effect on sponsors, especially if it is combined with an aggressive enforcement program. See notes 111-19 supra and accompanying text. 
characteristics as subjects in the original test. ${ }^{142}$ Humans also bring an element of subjectivity to tests which animals do not; some people might not report adverse reactions that others would. Finally, because clinical research involves a large number of persons and extends over a long period of time, ${ }^{143}$ the verification procedure would be slow and expensive.

2. Complete Third-Party Testing. An independent third-party testing system for drugs is envisioned in legislation introduced by Senator Gaylord Nelson. ${ }^{144}$ Under this proposal, the responsibility for clinical testing would be shifted from the sponsor to the Secretary of Health, Education, and Welfare (HEW). ${ }^{145}$ The government would either test the drugs itself or it would arrange for the tests to be conducted by independent contractors. ${ }^{146}$ Because these two systems have different advantages and disadvantages, they will be analyzed separately.

(a) Government testing. The principal advantage of government testing of new drugs is the elimination of the adverse consequences that result from the profit motivation that is connected with private testing. It is thought that government researchers would be less biased towards results favorable to the sponsor and the potential for deliberate distortion thereby would be decreased. ${ }^{147}$ In addition, proponents of this system claim that because there is less likelihood of bias, many of the current complicated regulations which are intended to protect the public would be simplified. ${ }^{148}$ For that reason and because of the centralization of testing in the government, it is believed the drug testing system "could be speeded up immeasurably." 149 Finally, it has been claimed that government testing would be less expensive because it would be better organized than the present system, where research is done in "a rather haphazard fashion with small funding [and] many, many investigators of questionable quality." 150

Whether the cost and efficiency advantages of a government testing system in fact would be realized depends on the scientific and organizational ability of the agency made responsible for the testing. Because that agency

142. Animals used in experiments have been raised in sterile laboratory environments. Humans who are test subjects often bring a variety of characteristics to the testing situation that may influence the effect that the drug has on them.

143. See notes 5-22 supra and accompanying text.

144. S. 1321, 94th Cong., 1st Sess. \& 513 (1975).

145. Id.

146. Id.

147. Competitive Problems in the Drug Industry (Part 10), at 3985 (testimony of George Nichols, Jr., M.D.).

148. Id.

149. Id.

150. Competitive Problems in the Drug Industry (Part 7), at 2770 (testimony of William O'Brien, M.D.). 
would be a government bureaucracy, some scientists doubt that research would be improved. ${ }^{151}$ In particular, critics point out that industry presently is a more efficient researcher than either the government or universities, ${ }^{152}$ presumably because it has a profit incentive to be so. The FDA believes that the work done by government testers may be no more accurate than that done by industry- $a$ fact it believes is supported by its testing of Red Dye No. 2, a food additive, where the FDA committed serious errors in its animal studies. ${ }^{153}$ In addition, there is some evidence that test subjects would not be any safer in government tests than they are in those sponsored by industry. ${ }^{154}$

Other disadvantages of government testing have been identified. The FDA, for example, believes that the government, as the only drug tester, would inevitably come to set research priorities, and since any monopoly, public or private, stagnates, it would be detrimentally determining the directions of drug innovation. ${ }^{155}$ The FDA also believes that if HEW were to conduct research on new drugs, it would be unable to judge impartially their safety and effectiveness during the approval process. ${ }^{156}$ Finally, several important questions related to government testing have not yet been resolved, such as the effect of government third-party testing on the research incentives of the pharmaceutical companies, ${ }^{157}$ and its effect on and the present shortage of qualified clinical researchers. ${ }^{158}$

Based on their perception of the disadvantages of government testing, the FDA and others believe it is too early to adopt such a proposal. ${ }^{159}$ Nevertheless, they have asserted that government testing should be considered a last resort after the other, less drastic proposals have been tried. ${ }^{160}$ Such a change is thought to be especially untimely because the FDA has just initiated efforts to guarantee more accurate data. ${ }^{161}$

151. Cf. New York Acad. of Medicine, supra note 24.

152. Cf. Examination of the Pharmaceutical Industry (Part S), at 2301 (testimony of Kenneth Melmon, M.D.).

153. Preclinical and Clinical Testing (Part 2), at 103-04.

154. See, e.g., Trippett, supra note 60 , at 72-73.

155. Preclinical and Clinical Testing by the Pharmaceutical Industry (Part 2), at 103; accord, Dowling, The Pharmaceutical Industry and the Doctor, supra note 138, at 75.

156. Examination of the Pharmaceutical Industry (Part 5), at 2163 (testimony of HEW Assistant Secretary for Health, Charles Edwards, M.D.).

157. See Comment, supra note 55, at 888 .

158. Examination of the Pharmaceutical Industry (Part 5), at 2163 (testimony of HEW Assistant Secretary for Health, Charles Edwards, M.D.).

159. Preclinical and Clinical Testing (Part 2), at 160 (testimony of Alexander M. Schmidt, M.D.); Examination of the Pharmaceutical Industry (Part 5), at 2301-02 (testimony of Kenneth Melmon, M.D.).

160. See, e.g., Preclinical and Clinical Testing (Part 2), at 160 (testimony of Alexander M. Schmidt, M.D.).

161. Examination of the Pharmaceutical Iridustry (Part 5), at 2163 (testimony of HEW 
In response to these assertions by the FDA, Senator Nelson has noted that although the FDA has been complaining about inaccurate and misleading data since 1966, its efforts have not yet produced desired improvements. ${ }^{162}$ Consequently, he believes that there is a substantial likelihood that in the future the FDA will indicate that it has found dishonest data while again urging that it be given more time to perfect the system. ${ }^{163}$

(b) Independent contracting. Under a system of independent contracting, the government would be responsible for hiring and paying independent researchers. ${ }^{164}$ The information produced would be given to both the pharmaceutical sponsor and the FDA for analysis. ${ }^{165}$ The cost of research could be assessed to the sponsor. ${ }^{166}$ As with government testing, the principle advantage of such independent contracting is that the researcher would be less biased towards results favorable to the sponsor and less likely to withhold information about problems with the drug's safety and efficacy. ${ }^{167}$

Changing only the payment mechanism, however, may not accomplish this result. Part of the possible bias in the existing system arises simply from the contacts between the researcher and the sponsor. ${ }^{168}$ To eliminate this potential source of influence, the investigators would have to be isolated from the sponsor for the duration of the research. ${ }^{169}$

Proponents of independent contracting assert that its feasibility has already been established. It has been noted that certain sections of the National Institutes of Health already perform the functions which the contracting agency would undertake. ${ }^{170}$ The current practice of awarding

Assistant Secretary for Health, Charles Edwards, M.D.); id. 2325 (testimony of Leon Goldberg, M.D.).

162. Preclinical and Clinical Testing (Part 2), at 157.

163. Id.

164. Competitive Problems in the Drug Industry (Part 10), at 3920 (testimony of William Bean, M.D.); Competitive Problems in the Drug Industry (Part 7), at 2768 (testimony of Kenneth Melmon, M.D.); How SAFE IS SAFE? 223-24.

165. Competitive Problems in the Drug Industry (Part 7), at 2777 (statement of Donald Mainland, M.D.).

166. See S. 1321, 94th Cong., 1st Sess. $\S 513$ (1975); Competitive Problems in the Drug Industry (Part 10), at 3920 (testimony of William Bean, M.D.).

167. Competitive Problems in the Drug Industry (Part 10), at 3920.

168. See text accompanying note 54 supra.

169. Competitive Problems in the Drug Industry (Part 7), at 2777 (statement of Donald Mainland, M.D.).

One scientist has suggested that the mere separation of the payment and the researcher would be a significant improvement without regard to whether the industry could or could not contact the investigator. Competitive Problems in the Drug Industry (Part 10), at 3986 (testimony of George Nichols, M.D.).

170. Competitive Problems in the Drug Industry (Part 7), at 2768 (statement of Donald Mainland, M.D.). There are also other examples of successful independent evaluation of new 
bids competitively on the basis of the quality of protocols, technical competence and economic efficiency could be continued. ${ }^{171}$ The progress of the testing could be monitored by periodic project site visits, as is routinely done with federal contracts. ${ }^{172}$

In addition, there is some indication that a rule restricting access of the sponsor to the researcher is feasible. The Cooperating Clinics Committee of the American Arthritis Association conducts independent clinical trials of drugs under the condition that, after the manufacturer has supplied the drug, its agents can have no further contact with the investigators until after completion of the trials. ${ }^{173}$ Any necessary communication is made through a coordinator's office. ${ }^{174}$

Supporters of this proposal have asserted that it has other advantages over a government testing system. The contracting agency could utilize leading medical experts both to choose the researchers and laboratories which would be involved in the testing and to do the actual testing. ${ }^{175}$ The proposal's supporters do not believe that the government could attract researchers with the same quality of expertise to work full time for the government in testing new drugs. ${ }^{176}$

While complete government testing or contracting may be feasible for clinical testing, it apparently would not work as well for animal testing. Animal research is closely related to drug innovation. Through animal testing, the sponsor can determine the potential therapeutic properties of compounds under consideration. ${ }^{177}$ Removal of even some animal tests from sponsors could undermine the basic process of drug development. Moreover, the FDA believes that contracting may be difficult because most of the country's expertise in toxicology is located within the pharmaceutical industry. Consequently, there are an insufficient number of independent animal testing laboratories to undertake the necessary research. ${ }^{178}$

drugs. Id. (statement of Donald Mainland, M.D., English Medical Research Council); Competitive Problems in the Drug Industry (Part 10), at 3920 (testimony of William Bean, M.D., National Vitamin Foundation and the Nutrition Foundation). The model of government brokering of research also was used successfully with the Corporation to Control Telstar. ConsuMERS REPORTS, Mar. 1963, at 136, reprinted in Interagency Coordination in Drug Research and Regulation, Part 3, at 1052.

171. How SAFE IS SAFE? 223.

172. Id.

173. Competitive Problems in the Drug Industry (Part 7), at 2777 (statement of Donald Mainland, M.D.).

174. Id.

175. Id. 2768 (testimony of George Nichols, M.D.).

176. Id.

177. Review Panel on New Drug Regulation, supra note 16, at 18.

178. Preclinical and Clinical Testing (Part 2), at 104. It appears likely that if the government were to adopt a program of independent contracting for animal testing, the supply of independent toxicology laboratories eventually would increase to meet the demand. 
Despite the fact that government contracting of drug research may appear to be a less drastic change in drug testing than direct government testing, it still would involve a considerable alteration of the present drug development process. Problems of coordination among the contractor, the FDA, and the sponsor must be worked out. In addition, the process would have to be arranged so that the contracting out of research does not unnecessarily prolong the drug development process.

It is difficult to anticipate all of the possible complications which might arise if the government does assume responsibility for contracting out research on new drugs. Thus, before any final decision is made to adopt this approach, it would seem wise to implement a pilot program that involves government testing of a limited number of drugs.

\section{CONCLUSIONS AND RECOMMENDATIONS}

Under the present drug testing system, there are few mechanisms to ensure that the FDA receives reliable data in its consideration of the safety and effectiveness of a new drug. Without accurate data, the agency may lack an adequate basis upon which to evaluate the risks and benefits associated with a drug's use. Serious questions can also be raised about the morality of human testing when data from such testing are not accurately presented to the FDA.

Despite the sponsor's financial interest in deriving precise information from clinical tests and the professionalism of researchers involved in testing, the possibility remains that data submitted to the agency will be at least unconsciously biased and, at worse, fraudulent. Likewise, criminal penalties for submission of fraudulent information and the FDA's monitoring of laboratory practices provide incentive for the submission of accurate information. However, these factors have not always prevented submission of fraudulent data and they are not useful mechanisms for deterring subtle bias in data analysis. Accordingly, five further steps should be taken to minimize problems of inaccurate and misleading test information.

First, the FDA already has proposed regulations concerning Good Laboratory Practice for Nonclinical Laboratories. The agency hopes to inspect each nonclinical laboratory every two years to determine if the laboratories are in compliance with the regulations. In addition to this inspection program, the FDA should use its authority for limited third-party testing to verify animal test information submitted to it. If such authority is limited to spot checks where sponsors have submitted misleading or inaccurate information in the past, limited third-party testing should serve as an additional incentive for the submission of reliable information. Spot checking would not slow the development process since it could be conducted simultaneously with the ongoing testing. 
This form of limited third-party testing is thought to be preferable to complete third-party testing for animal experimentation. While completely removing animal testing from sponsors to an independent third party is a more direct method by which to eliminate some of the possibility of bias or distortion, it may also create a research disincentive since the animal testing process is closely tied to sponsor innovation. Moreover, complete thirdparty testing could not be implemented as rapidly as the partial testing approach because presently animal testing expertise independent of the pharmaceutical industry is limited.

A second step would be for the FDA to finalize its guidelines for clinical research to ensure that sponsors are fully aware of the agency's requirements for such research. The inaccuracy and sloppiness of industrygenerated data apparently results in part from lack of guidance from the FDA regarding the research requirements. Thus such guidelines could reduce inefficiency in the testing process, thereby minimizing the possibility that test subjects would be exposed to risks unnecessarily. Clinical guidelines also would provide the FDA with a further basis for evaluating the industry submissions of information.

In addition, if, in conjunction with the release of guidelines, the FDA were to increase its supervisory role during the clinical investigational period for new drugs, the quality of data submitted as a result of clinical studies would be enhanced. For example, the FDA might institute conferences with the sponsor at critical times during the drug development process, such as prior to initiation of large-scale clinical trials.

As a fourth innovation, the FDA should utilize its present authority to impose administrative sanctions against anyone found to have submitted inaccurate or misleading material information or, where appropriate, recommend criminal prosecutions. The FDA has assigned too low a priority to enforcement of the provisions of the FDCA and those of its regulations that are intended to ensure the accuracy of data. Although the FDA must take care to avoid a relationship with the industry that is so adversarial as to be counter-productive, its behavior must also convince researchers and drug sponsors that sanctions will be imposed on those who submit inaccurate or misleading information.

Finally, a pilot program should be implemented whereby HEW would contract with independent parties for the clinical testing of a class of drugs which the FDA would choose based on its assessment of which class of drugs could benefit most from the program. Additional assurance of the accuracy of clinical research could be best implemented through such a program of government contracting. The other possible alternatives appear to be less advantageous than the contracting approach. Limited third-party testing to verify existing clinical research information would pose ethical 
problems and would be difficult, costly and time-consuming. Complete testing by the government would necessitate a sizable government bureaucracy which might not be as efficient or innovative as the private sector. By comparison, government contracting would be a lesser regulatory intrusion. But since it would be a substantial change from the present system, it is difficult to foresee all of the possible complications which might arise if government contracting is adopted. For that reason, a pilot program would be a reasonable method to approach the implementation of this proposal. 